\title{
Genetic variant of MIR4300HG is associated with progression of adolescent idiopathic scoliosis in a Chinese population
}

\author{
Yuwen Wang ${ }^{1,2+}$, Zhicheng Dai ${ }^{1,2+}$, Zhichong $\mathrm{Wu}^{2}$, Zhenhua Feng ${ }^{2}$, Zhen $\mathrm{Liu}^{2}$, Xu Sun², Leilei Xu ${ }^{2}$, Yong Qiu ${ }^{1,2}$ and \\ Zezhang Zhu $^{1,2^{*}}$
}

\begin{abstract}
Background: A recent genome-wide association study identified a susceptible locus in MIR4300HG gene that was associated with curve progression of adolescent idiopathic scoliosis (AIS) in the Japanese population. However, the association between the gene and curve progression in other populations remains unclear.

Methods: A cohort of 1952 AIS patients and 2495 healthy controls were included in the case-control analysis. In the case-only analysis, 747 patients were assigned to the progression group and 520 patients were assigned to the non-progression group, respectively. Rs35333564 was genotyped for all the subjects. Paraspinal muscles of 76 patients were collected for the analysis of gene expression. Chi-square test and ANOVA test were used for the intergroup comparison. Pearson correlation analysis was performed to investigate the relationship between the gene expression and curve magnitude.

Results: Variant rs35333564 was significantly associated with the curve severity of AIS ( $p=0.025)$, but not the development of AIS ( $p=0.418)$. Genotype GG was indicated by remarkably lower expression of MIR4300 ( $p=0.020)$ which was significantly correlated with curve magnitude $(p=0.010)$. As a predicted target gene of MIR4300, the expression of CRTC1 was negatively correlated with MIR4300 expression ( $p=0.012, r=-0.287)$ and positively correlated with curve severity $(p=0.025, r=0.257)$.

Conclusions: The association between rs35333564 and curve progression was successfully replicated in a Chinese AIS population. CRTC1 may be the target gene of MIR4300 that plays a role in the curve progression of AIS.
\end{abstract}

Keywords: Adolescent idiopathic scoliosis, MIR4300HG, Curve progression, Genetic variant

\section{Introduction}

Adolescent idiopathic scoliosis (AIS) is a complex spinal deformity that affects $2-3 \%$ of children aged $10-16$ years worldwide [1]. The curves in some AIS patients with an expected residual growth of the spine may progress to larger magnitude which commonly requires spinal fusion

\footnotetext{
* Correspondence: zhuzezhang@126.com

†Yuwen Wang and Zhicheng Dai contributed equally to this work. 'Department of Spine Surgery, Drum Tower Hospital Clinical College of Nanjing Medical University, Zhongshan Road 321, Nanjing 210008, China ${ }^{2}$ Department of Spine Surgery, Drum Tower Hospital of Nanjing University Medical School, Nanjing, China
}

surgery when exceeding $45^{\circ}$ [1]. Considering the significant psychological trauma and financial burden caused by surgery, accurate prediction of curve progression can undoubtedly facilitate early intervention with individualized strategy, ultimately leading to better prognosis and reduced negative effects from excessive treatment [2]. However, conventional predictive models using clinical predictors such as skeletal immaturity, initial Cobb angle, and vertebral rotation were not so effective to be used as diagnostic criteria [3]. More reliable prognostic

(c) The Author(s). 2021 Open Access This article is licensed under a Creative Commons Attribution 4.0 International License, which permits use, sharing, adaptation, distribution and reproduction in any medium or format, as long as you give appropriate credit to the original author(s) and the source, provide a link to the Creative Commons licence, and indicate if changes were made. The images or other third party material in this article are included in the article's Creative Commons. licence, unless indicated otherwise in a credit line to the material. If material is not included in the article's Creative Commons licence and your intended use is not permitted by statutory regulation or exceeds the permitted use, you will need to obtain permission directly from the copyright holder. To view a copy of this licence, visit http://creativecommons.org/licenses/by/4.0/ The Creative Commons Public Domain Dedication waiver (http://creativecommons.org/publicdomain/zero/1.0/) applies to the data made available in this article, unless otherwise stated in a credit line to the data. 
factors need to be identified to increase the accuracy of the predictive model.

Genetic components have been shown to play an important role in AIS curve progression, as evidenced by several zygotic twins and family studies [4-7]. It has been well documented that the combined effect of genetic variants may have better prediction for the prognosis of the complex disease [8, 9]. Ward et al. [10] developed the first DNA-based prognostic test "ScoliScore" to predict AIS curve progression in the Caucasians. However, the component SNPs of ScoliScore were not successfully replicated in the Chinese, the CanadianFrench, or the Japanese population, thus implying the importance of validation study when embedding new genetic markers in the predictive model of curve progression [11-14]. Recently, Ogura et al. [15] conducted a GWAS study and identified that a functional variant rs35333564, located in the host gene of microRNA MIR4300 (MIR4300HG), was associated with progression of AIS. However, there is a lack of replication study concerning the association of MIR4300HG with curve progression in other populations. The purpose of the present study was to validate the association of MIR4300HG with the progression of AIS and to further determine the target gene of MIR4300 that may be involved in the curve progression.

\section{Methods}

\section{Subject}

This retrospective study was approved by the institutional review board of Drum Tower Hospital of Nanjing University Medical School (Institutional Review Board no. 2019-066-01). Informed consent was obtained from all participants and guardians. We reviewed female AIS patients who visited our scoliosis center between July 2008 and September 2019 to determine whether they were eligible to be included in this study. Healthy participants were recruited during the physical examination before university admission. The following inclusion criteria were used: (1) AIS was diagnosed by clinical and radiological examination, (2) no history of braces or other conservative treatment, and (3) with Cobb angle more than $20^{\circ}$. Through the Adam's Forward Bend Test by a senior orthopedic surgeon (Y.Q), scoliosis in healthy individuals was excluded [16]. Overall, there were 1952 patients and 2495 controls included in the case-control analysis.

For the case-only analysis, we divided AIS patients into the progression and non-progression groups. Patients with Cobb angle more than $50^{\circ}$ and Risser grade less than 3 were assigned to the progression group, and patients with Cobb angle less than $30^{\circ}$ and Risser grade more than 3 at the final follow-up were assigned to the non-progression group. Ultimately, 747 patients were assigned to the progression group and 520 patients were assigned to the non-progression group, respectively. At each visit, standing posteroanterior radiographs of the spine were obtained and demographic characteristics were recorded, including Cobb angle of the main curve, Risser sign, BMI, and menarche age.

\section{Genotyping of the target SNP}

Blood samples from each patient were collected for the extraction of genomic DNA following standard methods (Qiagen K.K., Tokyo, Japan). We used the TaqMan SNP genotyping method to genotype rs35333564 of MIR4300HG on the ABI PRISM 7900HT sequence detection system (Applied Biosystems, Foster City, CA). To verify the reliability of genotyping results, $20 \%$ samples were randomly selected. The reproducible rate was $100 \%$.

\section{Expressions of the genes in the paraspinal muscles}

The paraspinal muscles of the proximal vertebral segments of 76 patients were collected during the operation. Total RNA was isolated using Trizol reagent (Invitrogen, Carlsbad, CA) in accordance with the protocol of the manufacturer. To explore the expression level of MIR4300, complementary DNA was synthesized using a specific primer: 5'-CCTGTT GTCTCCAGCCACAAAAGAGCACAATATTTCAGGA GACAACAGGGAAGTAG-3'. Quantitative polymerase chain reaction (PCR) analysis used the following primers: forward 5'-CGGGCTGGGAGCTGGA-3', reverse 5' CAGCCACAAAAGAGCACAAT-3' for MIR4300; forward 5' -CTCGCTTCGGCAGCACA-3', reverse 5' -AACGCTTC ACGAATTTGCGT-3' for the endogenous control gene U6. Moreover, to further analyze the target gene of MIR4300 that exerts effect on the curve progression of AIS, a list of 55 genes was predicted using an on-line tool (TargetScan Human7.0 and miRWalk2.0 database) and the primers were designed for each gene as shown in Additional file 1. The gene expression was detected using a SYBR green-based real-time quantitative PCR assay (Toyobo Co., LDT, Osaka, Japan) as formerly described [17]. Melting point curve analysis was performed after cycling to ensure the quality of qPCR products. The $2^{-\Delta \Delta C t}$ method was used to determine the quantitative measurements.

\section{Statistical analysis}

Statistical analysis was performed by using SPSS software (version 20.0; SPSS Inc., Chicago, IL). The Hardy-Weinberg equilibrium (HWE) was tested in the AIS patients and healthy controls, using a $\chi^{2}$ goodness-of-fit test. Intergroup comparisons of the genotype and allele frequency were analyzed using the chi-square test. Minor allele $G$ was used as a reference to calculate the odds ratio (OR). The ANOVA test was used to compare with expression of MIR4300 among different genotypes of rs35333564. The Pearson 
Table 1 Baseline characteristics of the subjects enrolled in the case-only analysis

\begin{tabular}{llll}
\hline & Progression group & Non-progression group & $\boldsymbol{p}$-value \\
\hline Initial age (years) & $13.2 \pm 2.4$ & $13.0 \pm 2.3$ & 0.129 \\
Menarche age (years) & $13.3 \pm 1.3$ & $13.1 \pm 1.2$ & 0.128 \\
BMI $\left(\mathrm{kg} / \mathrm{m}^{2}\right)$ & $18.2 \pm 2.3$ & $17.9 \pm 2.4$ & 0.152 \\
Cobb angle $\left(^{\circ}\right)$ & $65.8 \pm 9.7$ & $25.9 \pm 3.5$ & $<0.001$ \\
Initial Risser sign & $0.6 \pm 0.9$ & $4.3 \pm 0.5$ & $<0.001$ \\
\hline
\end{tabular}

correlation analysis was performed to investigate the relationship between the expression level of MIR4300 and the predicted target genes, as well as the relationship between the gene expression level and the curve severity. $p<0.05$ was considered to be statistically significant.

\section{Results}

\section{Clinical characteristics of the participants}

In the case-control analysis, the mean age was $13.6 \pm 2.8$ years for the AIS patients $(n=1952)$ and $19.2 \pm 3.6$ years for healthy controls $(n=2495)$. For AIS patients, the mean curve magnitude was $36.8 \pm 3.2^{\circ}$ (range 22-66 ${ }^{\circ}$ ), the mean BMI was $17.5 \pm 3.4 \mathrm{~kg} / \mathrm{m}^{2}$ (range, 16.3-24.6 $\mathrm{kg} / \mathrm{m}^{2}$ ), and the mean menarche age was $12.3 \pm 1.8$ years (range, 10.2-15.3 years), respectively. There were 1218 (62.4\%) cases with main thoracic curve, 476 (24.3\%) cases with double major curve, and 258 (13.3\%) cases with major lumbar curves, respectively.

As shown in Table 1, for the case-only analysis, the two groups were matched in terms of initial age, menarche age, and BMI $(13.2 \pm 2.4$ years vs. $13.0 \pm 2.3$ years, $p$ $=0.129$ for initial age; $13.3 \pm 1.3$ years vs. $13.1 \pm 1.2$ years, $p=0.128$ for menarche age; $18.2 \pm 2.3 \mathrm{~kg} / \mathrm{m}^{2}$ vs. $17.9 \pm 2.4 \mathrm{~kg} / \mathrm{m}^{2}$ for BMI, $p=0.152$ ). There were remarkably higher Cobb angle and less initial Risser sign in the progression group than in the non-progression group $\left(65.8^{\circ} \pm 9.7^{\circ}\right.$ vs. $25.9^{\circ} \pm 3.5^{\circ}, p<0.001$ for Cobb angle; $0.6 \pm 0.9$ vs. $4.3 \pm 0.5, p<0.001$ for Risser sign).

For the 76 patients included in the gene expression analysis, the average curve magnitude was $64.1^{\circ} \pm 6.7^{\circ}$ (range, 53 to $78^{\circ}$ ). The mean age and Risser grade were $13.2 \pm 1.6$ years and $4.3 \pm 0.7$, respectively.

\section{Association of the rs35333564 with the onset of AIS}

Genotype frequency in the patients and the healthy controls revealed no significant departure from the Hardy-Weinberg equilibrium $(p>0.05)$. The distribution of genotype and allele frequency of the subjects is summarized in Table 2. There was no significant difference regarding genotype frequency (3.2\% vs. $2.8 \%, p=0.418)$ or the minor allele frequency $(16.6 \%$ vs. $15.6 \%, p=0.181)$ between the two groups.

\section{Association of rs35333564 with the curve progression}

As shown in Table 3, there was significant difference between curve progression group and non-progression group regarding both genotype frequency (3.1\% vs. $1.3 \%$, $p=0.025)$ and minor allele frequency $(17.5 \%$ vs. $13.7 \%$, $p=0.011$ ) of rs35333564 in MIR4300 gene. Furthermore, the curve in adolescent idiopathic patients with an allele $\mathrm{G}$ will be prone to progression, with an OR value of 1.339 (95\% CI $=1.072-1.671)$. For tissue expression analysis, there were 11 cases with genotype GG, 15 cases with genotype GC, and 50 cases with genotype AA. Patients with genotype GG were found to have significantly lower MIR4300 expression than those with genotype AA $(0.000403 \pm 0.000188$ vs. $0.000637 \pm$ 0.000306, $p=0.020$ ) (Fig. 1).

\section{Relationship between gene expression level and clinical features of the patients}

The expression of MIR4300 was significantly correlated with curve magnitude ( $r=-0.294, p=0.01$ ) (Fig. 2). Among the 55 predicted target genes, the expression level of CRTC1 was found inversely correlated with that

Table 2 Distribution of the genotype and allele frequency of rs35333564 in AIS patients and healthy controls

\begin{tabular}{|c|c|c|c|c|c|c|c|c|c|}
\hline & \multicolumn{3}{|c|}{ Genotype } & \multirow[t]{2}{*}{$p$} & \multicolumn{2}{|l|}{ Allele } & \multirow[t]{2}{*}{$p$} & \multirow{2}{*}{$\begin{array}{l}\text { Odds ratio } \\
(95 \% \mathrm{Cl})\end{array}$} & \multirow[t]{2}{*}{$p^{a}$} \\
\hline & GG & AG & AA & & G & $A$ & & & \\
\hline & & & & 0.418 & & & 0.181 & $\begin{array}{l}1.08 \\
(0.96-1.21)\end{array}$ & \\
\hline $\begin{array}{l}\text { Patients } \\
(n=1952)\end{array}$ & $\begin{array}{l}62 \\
(3.20 \%)\end{array}$ & $\begin{array}{l}524 \\
(26.8 \%)\end{array}$ & $\begin{array}{l}1366 \\
(70.0 \%)\end{array}$ & & $\begin{array}{l}648 \\
(16.6 \%)\end{array}$ & $\begin{array}{l}3256 \\
(83.4 \%)\end{array}$ & & & 0.179 \\
\hline $\begin{array}{l}\text { Controls } \\
(n=2495)\end{array}$ & $\begin{array}{l}69 \\
(2.80 \%)\end{array}$ & $\begin{array}{l}638 \\
(25.6 \%)\end{array}$ & $\begin{array}{l}1788 \\
(71.6 \%)\end{array}$ & & $\begin{array}{l}776 \\
(15.6 \%)\end{array}$ & $\begin{array}{l}4214 \\
(84.4 \%)\end{array}$ & & & 0.187 \\
\hline
\end{tabular}

Cl confidential interval

$p^{a}$ indicates the $p$ value of the HWE test 
Table 3 Distribution of the genotype and allele frequency of rs35333564 in the progression group and non-progression group

\begin{tabular}{|c|c|c|c|c|c|c|c|c|}
\hline & \multicolumn{3}{|c|}{ Genotype } & \multirow[t]{2}{*}{$p$} & \multicolumn{2}{|l|}{ Allele } & \multirow[t]{2}{*}{$p$} & \multirow{2}{*}{$\begin{array}{l}\text { Odds ratio } \\
(95 \% \mathrm{Cl})\end{array}$} \\
\hline & $\overline{\mathrm{GG}}$ & AG & AA & & $\overline{\mathbf{G}}$ & $A$ & & \\
\hline & & & & 0.025 & & & 0.011 & $\begin{array}{l}1.34 \\
(1.07-1.67)\end{array}$ \\
\hline $\begin{array}{l}\text { Progression group } \\
(n=747)\end{array}$ & $\begin{array}{l}23 \\
(3.1 \%)\end{array}$ & $\begin{array}{l}215 \\
(28.8 \%)\end{array}$ & $\begin{array}{l}509 \\
(68.1 \%)\end{array}$ & & $\begin{array}{l}261 \\
(17.5 \%)\end{array}$ & $\begin{array}{l}1233 \\
(82.5 \%)\end{array}$ & & \\
\hline $\begin{array}{l}\text { Non-progression group } \\
(n=520)\end{array}$ & $\begin{array}{l}7 \\
(1.3 \%)\end{array}$ & $\begin{array}{l}128 \\
(24.6 \%)\end{array}$ & $\begin{array}{l}385 \\
(74.1 \%)\end{array}$ & & $\begin{array}{l}142 \\
(13.7 \%)\end{array}$ & $\begin{array}{l}898 \\
(86.3 \%)\end{array}$ & & \\
\hline
\end{tabular}

Cl confidential interval

of MIR4300 with statistical significance $(r=-0.287, p=$ 0.012) (Table 4). Moreover, there was a positive correlation between the expression of CRTC1 and curve magnitude $(r=0.257, p=0.025)$ (Fig. 3). No significant correlation was found between the expression of CRTC1 and other clinical parameters including BMI $(r=0.100$, $p=0.390)$ or menarche age $(r=0.076, p=0.516)$.

\section{Discussion}

Most of previously reported genetic markers predicting curve progression in AIS patients, including SNPs in IGF1 and ESR2, were not successfully replicated by other studies $[18,19]$. Therefore, it is necessary to verify the association of reported locus with AIS progression in different ethnic populations. Ogura et al. [15] reported a functional variant rs35333564 located in MIR4300HG was associated with the progression of AIS in the Japanese population. Based on a large cohort of subjects, our study successfully validated that rs35333564 of MIR4300HG was associated with AIS progression in a Chinese population. Moreover, allele G in rs35333564 could significantly add to the risk of curve progression with an OR of 1.339, which is slightly lower than that reported by Ogura et al. [15]. In addition, we also explored the relationship of the locus with the onset of AIS by genotyping in both AIS patients and normal controls, while no significant association was observed. To summarize, rs35333564 of MIR4300HG may not be the trigger for the development of AIS but more likely the fuel driving curve progression.

To explore the potential functional role of rs35333564, for the first time, we evaluated the relative expression level of MIR4300 in the paraspinal muscles among patients with different genotypes of rs35333564. Patients with genotype GG were found to have remarkably lower tissue expression of MIR4300 than those with genotype AA. This finding was in line with the luciferase assay performed by Ogura et al. [15], which showed that allele $\mathrm{G}$ can remarkably lower the transcriptional activity of the pGL3 promoter vector. Interestingly, the tissue expression level of MIR4300 was found significantly correlated with curve severity in the current study. Taken together, it was plausible that rs35333564 may play a functional role in the curve progression by downregulating the tissue expression of MIR4300.

To date, the function of MIR4300 remains unknown. As reported in the study of Ogura et al. [15], 55 genes were predicted to be the potential target of MIR4300. Through the expression analysis of these 55 genes, we further identified that CRTC1 was remarkably correlated

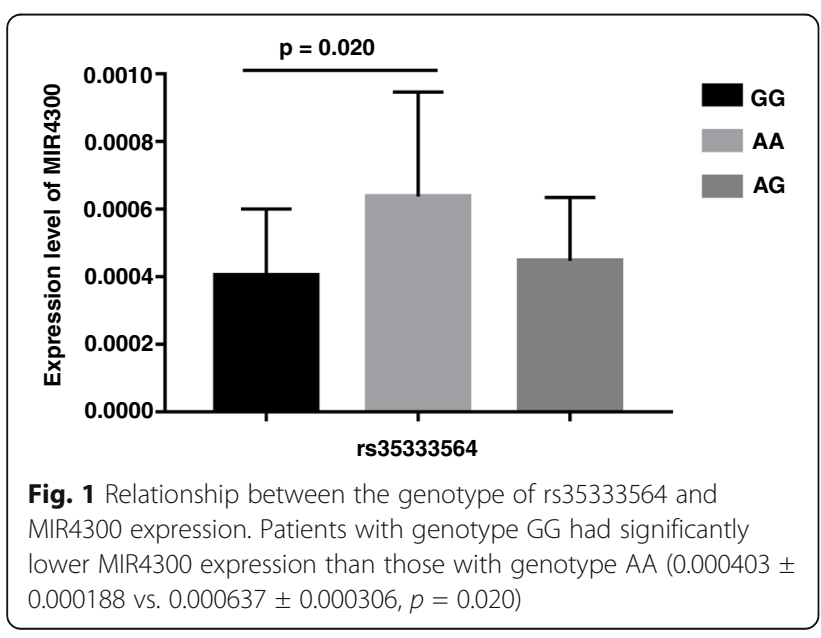

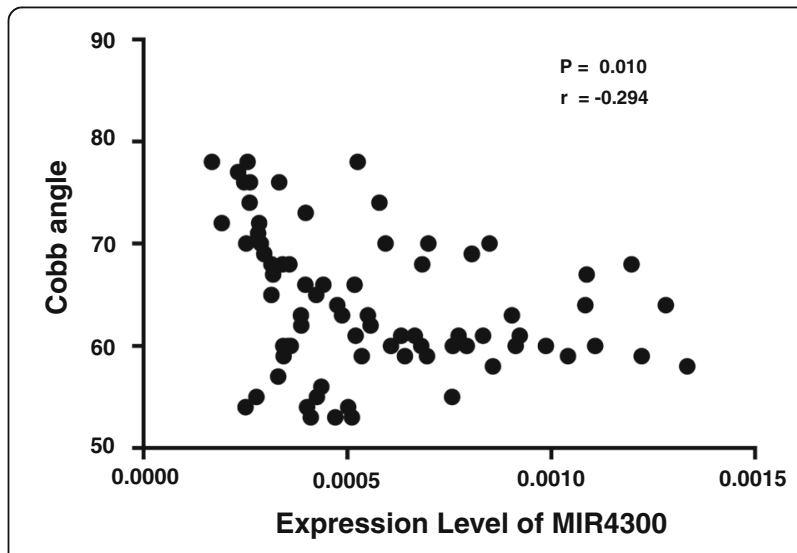

Fig. 2 The correlation between MIR4300 expression and Cobb angle in AIS patients. The expression of MIR4300 was significantly correlated with Cobb angle in AIS patients 
Table 4 The correlation between MIR4300 expression and CRTC1 expression in AIS patients. The expression level of CRTC1 was found inversely correlated with that of MIR4300

\begin{tabular}{lllll}
\hline Gene & CRTC1 & MIR4300 & $p$-value & $\boldsymbol{r}$ \\
\hline Mean expression & $0.00155 \pm 0.00032$ & $0.00057 \pm 0.00029$ & 0.012 & -0.287 \\
\hline
\end{tabular}

with MIR4300 expression as well as the curve severity. Berdeaux et al. [20] reported that CREB-CRTCs are key cAMP effectors, which promote muscle adaptation by activating transcription programs, thereby increasing skeletal muscle performance. Considering histochemical and physiological abnormalities in muscles of patients with idiopathic scoliosis [21], we suggested that CRTC1 may be the target gene of MIR4300 that may function in the curve progression. Further studies are warranted to investigate the underlying mechanism by in vivo and intro experiments.

In the present study, we validated the association between genetic variants of MIR4300 with curve progression by genotyping in a relatively large population. Moreover, we identified CRTC1 as the potential target gene of MIR4300 and found that the expression level of MIR4300 and CRTC1 in paraspinal muscles was significantly correlated with curve magnitude. Thus, we speculate that the miRNA encoded by MIR4300 were involved in the progression via regulating the expression of CRTC1. There are two limitations in the current study that need to be mentioned. Firstly, we only evaluated MIR4300 expression in muscle samples as few patients agreed to donate other tissues; further studies need to include more AIS-related tissues for the evaluation of MIR4300 expression. Secondly, only AIS patients who underwent surgical intervention (Cobb angle exceeds $50^{\circ}$ ) were enrolled in the expression analysis which could bias the results. Therefore, the association of MIR4300 expression with curve severity should be interpreted cautiously.

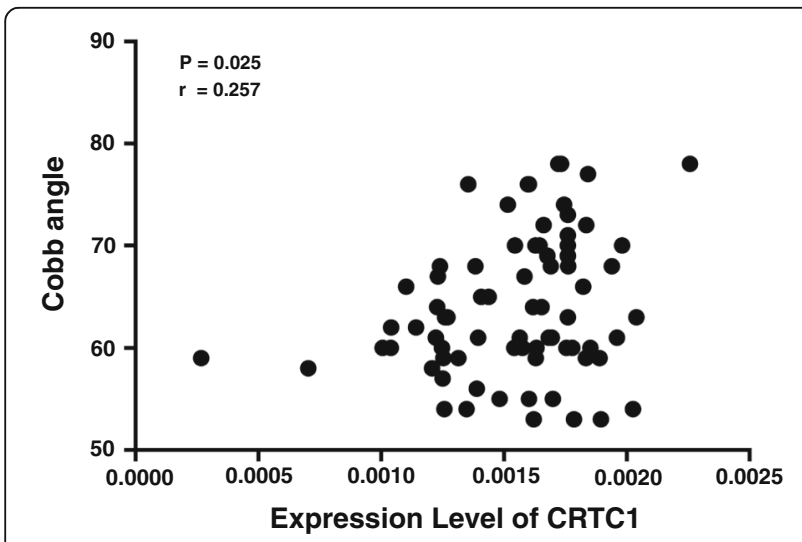

Fig. 3 The correlation between CRTC1 expression and Cobb angle in AIS patients. The expression of CRTC1 was significantly correlated with Cobb angle in AlS patients

\section{Conclusions}

The association between rs35333564 and curve progression was successfully replicated in a Chinese AIS population. Allele $\mathrm{G}$ can add to the risk of curve progression possibly through the down-regulation of MIR4300. CRTC1 may be the target gene of MIR4300 that plays a role in the curve progression of AIS. Further studies are warranted to explore the molecular mechanism underlying the effect of MIR4300 on curve progression in AIS patients.

Abbreviation

AIS: Adolescent idiopathic scoliosis

\section{Supplementary Information}

The online version contains supplementary material available at https://doi. org/10.1186/s13018-021-02455-w.

Additional file 1: Table S1. Primers of the 55 predicted target genes of MIR4300.

\section{Acknowledgements}

Not applicable.

\section{Authors' contributions}

YWW was responsible for the design and writing of the manuscript. ZCD, $Z C W$, and ZHF were responsible for the collection of the data and images. $Z L, X S$, and $X L L$ were responsible for the statistics and analysis of the data. $Y Q$ and ZZZ were responsible for the design and revision of the article. All authors read and approved the final manuscript.

\section{Funding}

This work was supported by the Natural Science Foundation of China (No. 81871747 \& No.81661168013, No. 8197090027, No. 81772304) and Joint Research Scheme sponsored by the National Natural Science Foundation of China and the Research Grants Council of the Hong Kong Special

Administrative Region (N_CUHK416/16).

Availability of data and materials

The data generated or analyzed during this study are included in this published article [and its supplementary information files].

\section{Declarations}

Ethics approval and consent to participate

This study was approved by the local Ethics Committee of The Affiliated Hospital of Drum Tower Hospital of Nanjing University Medical School (Institutional Review Board no. 2019-066-01). Written consent was obtained from all participants.

Consent for publication

We have obtained written consent to publish from the participant to report individual patient data.

\section{Competing interests}

The authors declare that they have no competing interests. 
Received: 20 March 2021 Accepted: 4 May 2021

Published online: 13 May 2021

\section{References}

1. Weinstein SL, Dolan LA, Cheng JC, Danielsson A, Morcuende JA. Adolescent idiopathic scoliosis. Lancet. 2008;371(9623):1527-37. https://doi.org/10.1016/ s0140-6736(08)60658-3.

2. Negrini S, Minozzi S, Bettany-Saltikov J, Chockalingam N, Grivas TB, Kotwicki T, et al. Braces for idiopathic scoliosis in adolescents. Cochrane Database Syst Rev. 2015:Cd006850. https://doi.org/10.1002/14651858.CD006850.pub3.

3. Noshchenko A, Hoffecker L, Lindley EM, Burger EL, Cain CM, Patel W, et al. Predictors of spine deformity progression in adolescent idiopathic scoliosis: a systematic review with meta-analysis. World J Orthop. 2015;6(7):537-58. https://doi.org/10.5312/wjo.v6.i7.537.

4. Kesling KL, Reinker KA. Scoliosis in twins. A meta-analysis of the literature and report of six cases. Spine (Phila Pa 1976). 1997;22(17):2009-14; discussion 2015. https://doi.org/10.1097/00007632-199709010-00014

5. Andersen MO, Thomsen K, Kyvik KO. Adolescent idiopathic scoliosis in twins: a population-based survey. Spine (Phila Pa 1976). 2007;32(8):927-30. https://doi.org/10.1097/01.brs.0000259865.08984.00

6. Inoue M, Minami S, Kitahara H, Otsuka Y, Nakata Y, Takaso M, et al. Idiopathic scoliosis in twins studied by DNA fingerprinting: the incidence and type of scoliosis. J Bone Joint Surg Br. 1998;80(2):212-7. https://doi. org/10.1302/0301-620x.80b2.7544.

7. Ward K, Ogilvie J, Argyle V, Nelson L, Meade M, Braun J, et al. Polygenic inheritance of adolescent idiopathic scoliosis: a study of extended families in Utah. Am J Med Genet A. 2010;152A(5):1178-88. https://doi.org/10.1002/a jmg.a.33145.

8. Hu C, Jia W. Diabetes in China: Epidemiology and genetic risk factors and their clinical utility in personalized medication. Diabetes. 2018;67(1):3-11. https://doi.org/10.2337/dbi17-0013.

9. Kamps R, Brandao RD, Bosch BJ, Paulussen AD, Xanthoulea S, Blok MJ, et al. Next-generation sequencing in oncology: genetic diagnosis, risk prediction and cancer classification. Int J Mol Sci. 2017;18(2). https://doi.org/10.3390/ ijms18020308.

10. Ward K, Ogilvie JW, Singleton MV, Chettier R, Engler G, Nelson LM. Validation of DNA-based prognostic testing to predict spinal curve progression in adolescent idiopathic scoliosis. Spine (Phila Pa 1976). 2010; 35(25):E1455-64. https://doi.org/10.1097/BRS.0b013e3181ed2de1.

11. Xu L, Qin X, Sun W, Qiao J, Qiu Y, Zhu Z. Replication of association between 53 single-nucleotide polymorphisms in a DNA-based diagnostic test and AIS progression in Chinese Han population. Spine (Phila Pa 1976). 2016; 41(4):306-10. https://doi.org/10.1097/BRS.0000000000001203.

12. Roye BD, Wright ML, Matsumoto H, Yorgova P, McCalla D, Hyman JE, et al An independent evaluation of the validity of a DNA-based prognostic test for adolescent idiopathic scoliosis. J Bone Joint Surg Am. 2015;97(24):19948. https://doi.org/10.2106/JBJS.0.00217.

13. Ogura Y, Takahashi Y, Kou I, Nakajima M, Kono K, Kawakami N, et al. A replication study for association of 53 single nucleotide polymorphisms in a scoliosis prognostic test with progression of adolescent idiopathic scoliosis in Japanese. Spine (Phila Pa 1976). 2013;38(16):1375-9. https://doi.org/10.1 097/BRS.0b013e3182947d21.

14. Tang QL, Julien C, Eveleigh R, Bourque G, Franco A, Labelle H, et al. A replication study for association of 53 single nucleotide polymorphisms in ScoliScore test with adolescent idiopathic scoliosis in French-Canadian population. Spine (Phila Pa 1976). 2015;40(8):537-43. https://doi.org/10.1097/ brs.0000000000000807.

15. Ogura Y, Kou I, Takahashi Y, Takeda K, Minami S, Kawakami N, et al. A functional variant in MIR4300HG, the host gene of microRNA MIR4300 is associated with progression of adolescent idiopathic scoliosis. Hum Mol Genet. 2017;26(20):4086-92. https://doi.org/10.1093/hmg/ddx291.

16. Capasso G, Maffulli N, Testa $V$. The validity and reliability of measurements in spinal deformities: a critical appraisal. Acta Orthop Belg. 1992;58(2):126-35.

17. Wu Z, Wang Y, Xia C, Feng Z, Qiu Y, Cheng JC, et al. PIEZO2: a novel molecule involved in the development of AIS. Spine (Phila Pa 1976). 2020; 45(3):E120-5. https://doi.org/10.1097/BRS.0000000000003224.

18. Zhao L, Roffey DM, Chen S. Association between the estrogen receptor beta (ESR2) Rs1256120 single nucleotide polymorphism and adolescent idiopathic scoliosis: a systematic review and meta-analysis. Spine (Phila Pa 1976). 2017:42(11):871-8. https://doi.org/10.1097/BRS.0000000000001932.
19. Guan M, Wang H, Fang H, Zhang C, Gao S, Zou Y. Association between IGF1 gene single nucleotide polymorphism (rs5742612) and adolescent idiopathic scoliosis: a meta-analysis. Eur Spine J. 2017;26(6):1624-30. https:// doi.org/10.1007/s00586-016-4742-7.

20. Berdeaux R, Hutchins C. Anabolic and pro-metabolic functions of CREBCRTC in skeletal muscle: advantages and obstacles for type 2 diabetes and cancer cachexia. Front Endocrinol (Lausanne). 2019;10:535. https://doi.org/1 0.3389/fendo.2019.00535.

21. Maffulli N. Histochemical and physiological studies in idiopathic scoliosis. Ital J Orthop Traumatol. 1990;16(1):61-71.

\section{Publisher's Note}

Springer Nature remains neutral with regard to jurisdictional claims in published maps and institutional affiliations.

\section{Ready to submit your research? Choose BMC and benefit from:}

- fast, convenient online submission

- thorough peer review by experienced researchers in your field

- rapid publication on acceptance

- support for research data, including large and complex data types

- gold Open Access which fosters wider collaboration and increased citations

- maximum visibility for your research: over $100 \mathrm{M}$ website views per year

At BMC, research is always in progress.

Learn more biomedcentral.com/submissions 